\title{
Teaching sustainability as complex systems approach: a sustainable development goals workshop
}

Sustainable development goals workshop

\author{
Jana M. Weber
}

Department of Chemical Engineering and Biotechnology, University of Cambridge, Cambridge, UK and CDI (Chemical Data Intelligence) Pte Ltd, Singapore, Singapore

Constantin P. Lindenmeyer

Goldbeck Solar GmbH, Hirschberg an der Bergstraße, Germany

\section{Pietro Liò}

Department of Computer Science and Technology, University of Cambridge, Cambridge, UK, and

\section{Alexei A. Lapkin}

Department of Chemical Engineering and Biotechnology,

University of Cambridge, Cambridge, UK; CDI (Chemical Data Intelligence) Pte Ltd, Singapore, Singapore and Cambridge Centre for Advanced Research and Education in Singapore, CARES Ltd, Singapore, Singapore

\begin{abstract}
Purpose - Approaches to solving sustainability problems require a specific problem-solving mode, encompassing the complexity, fuzziness and interdisciplinary nature of the problem. This paper aims to promote a complex systems' view of addressing sustainability problems, in particular through the tool of network science, and provides an outline of an interdisciplinary training workshop.

Design/methodology/approach - The topic of the workshop is the analysis of the Sustainable Development Goals (SDGs) as a political action plan. The authors are interested in the synergies and tradeoffs between the goals, which are investigated through the structure of the underlying network. The authors use a teaching approach aligned with sustainable education and transformative learning.
\end{abstract}

(C) Jana M. Weber, Constantin P. Lindenmeyer, Pietro Liò and Alexei A. Lapkin. Published by Emerald Publishing Limited. This article is published under the Creative Commons Attribution (CC BY 4.0) licence. Anyone may reproduce, distribute, translate and create derivative works of this article (for both commercial and non-commercial purposes), subject to full attribution to the original publication and authors. The full terms of this licence may be seen at http://creativecommons.org/ licences/by/4.0/legalcode

JMW and CPL gratefully acknowledge the German Academic Scholarship Foundation and Alumni Association as funding bodies for the seminar and Tim Deisemann and Lisa Oswald as coorganisers. They thank all participants of the workshop for their enthusiasm, and all other lecturers for developing high-quality course concepts. They thank Ann-Kristin Winkens for fruitful input during the initial phase of the workshop design and Sebastian Ahnert for valuable feedback. JMW acknowledges the Department of Chemical Engineering and Biotechnology of the University of Cambridge for funding of her PhD studentship. This study was in part funded by National Research Foundation (NRF), Prime Minister's Office, Singapore under its Campus for Research Excellence and Technological Enterprise (CREATE) program as a part of the Cambridge Centre for Advanced Research and Education in Singapore Ltd (CARES).

Received 11 June 2020 Revised 18 October 2020 11 December 2020 Accepted 14 December 2020 
IJSHE 22,8

Findings - Methodologies from network science are experienced as valuable tools to familiarise students with complexity and to handle the proposed case study.

Originality/value - To the best of the authors' knowledge, this is the first work which uses network terminology and approaches to teach sustainability problems. This work highlights the potential of network science in sustainability education and contributes to accessible material.

Keywords Sustainability, Higher education, Complex systems, Education for sustainable development, Sustainable development goals (SDGs),

Workshop development

Paper type Research paper

\section{Introduction}

Sustainability problems are without doubt among the main concerns of the present, and cover almost every aspect of society. Such class of socio-ecological dilemmas is well-recognised as wicked problems (Rittel and Webber, 1973). Wicked problems are complex issues, which lack clear definition and which may not be solved through traditional modes of decision-making. They are not necessarily morally wicked, but problematic as their solutions resist usual attempts to solve them and bring further, often unforeseen, implications, with them. One may want to contrast them to tame problems, for which our scientific knowledge and common procedures have been developed (Brown et al., 2010; Rittel and Webber, 1973). Sustainability problems are a well-known example of wicked problems; they show difficulties in problem formulation, may have multiple, but not compatible solutions, are unique, consist of competing objectives, and are described by open-ended timeframes (Lotz-Sisitka et al., 2015; Seager et al., 2012). Thus, a challenge has arisen for educational institutions to equip students with the necessary skills to comprehend and solve problems of such nature.

An education, which trains students to handle multidisciplinarity, critical, as well as systems thinking, and interpersonal skills has frequently been illustrated as a path forward in the field of sustainability education (Filho and Dahms, 2018; Hermann and Bossle, 2020; Hoffmann and Siege, 2018; Iwaniec et al., 2014; Wals, 2012; Warburton, 2003). Warburton argues that, inter alia, students should spend time on the illustration of interconnections and dependencies and should learn to work with dynamic, rather than static, structures and processes (Warburton, 2003). Fenner et al. follow a similar line of argumentation when outlining that for sustainability in engineering education, understanding complexity and its relationships should be the starting point (Fenner et al., 2005). Breadth, alongside depth, of study will make the formulation of holistic approaches possible and an engineer will be required to learn:

- handling of ill-defined problems;

- team-work and communication skills; and

- critical evaluations (Fenner et al., 2005).

Perdan et al. outline in their work that the Sustainable Development Panel has advised to integrate sustainable development into specialist courses, which differs from the aforementioned multi-disciplinary approaches (Perdan et al., 2000). Allen-Gil and co-workers recognise the problems that a multi-disciplinary education may bring about; for example, that many environmental studies programs suffer from a lack of curricular coherence, shallow and too diverse thematic foci, and a lack of program vision and planning. Consequently they solve the problem through bringing together the curricula with a community project (Allen-Gil et al., 2005). Pappas et al. outlined their approach to teaching sustainability based on the Bloom's Taxonomy of Educational Objectives. Students gradually understand and apply complex thinking and move higher through the 
educational objectives (Pappas et al., 2013). Some works highlight the importance of including sustainability competencies in the education of educators (Albareda-Tiana et al., 2018; Bourn et al., 2017; Mulà et al., 2017), while another focus is the pedagogic approach to develop sustainability competencies (Lozano et al., 2019; Seatter and Ceulemans, 2017). Altogether, educators must continue working for an educational paradigm, which prepares students for the new challenges faced (Davidson et al., 2010), as future leaders, teachers, and experts in multiple disciplines in our society (Bartels and Parker, 2012; Bauer et al., 2018).

One of the main challenges for the educator is finding appropriate means that lead to the diverse set of required skills. Within this work, we pose and answer the question if mathematical methods of complex systems study are beneficial for education for sustainable development (ESD). We present a workshop, where network science is used to investigate a relevant sustainability case study, the complexity and interdependence of Sustainable Development Goals (SDGs). Our work concisely outlines consideration about the term and the concept of sustainability, but is based on the understanding of sustainable development established in Our Common Future (World Commission on Environment and Development, 1987).

\section{Contextual background}

In this section, we provide background information on network science, we introduce the SDGs and we argue their suitability as a case study.

\subsection{Network science}

A street network, the brain, a social network, food webs and the internet - we find networks everywhere. Our understanding of networks is still incomplete, however most important to comprehend today's problems (Barabási and Bonabeau, 2003).

Network science, broadly speaking, means analysis of problems through the study of their graph representations. While the exact history of network science may be contestable (Barabási, 2016; Barnes and Harary, 1983), the closeness to the discipline of graph theory, a subfield of mathematics, is widely recognised, yet not often discussed in detail (Barnes and Harary, 1983). Network science deals with complex graphs, exhibiting non-trivial patterns, whereas in graph theory the focus is on graphs with more defined structures (Derrible and Kennedy, 2011). As complexity governs many natural, social, or technological systems, network science is a highly interdisciplinary research field (Börner et al., 2007). One of the key findings in network science is that common organising principles form the structure of many real-world complex systems (Barabási, 2016), thus a mutual set of mathematical tools can be beneficial.

A graph consists of vertices, commonly associated with subjects or objects of interest, and edges, commonly associated with a relationship between the subjects/objects. In literature, the expressions graph and network, as well as vertex and node, and edge and link, are commonly used interchangeably (Barabási, 2016). Both graph units may have additional properties. An edge, for instance, can be directed or undirected, adding information on the nature of the interaction between the vertices. It can also be weighted to provide information about the strength of the relationship. Vertices can be of a certain type, offering information on the nature of the represented subject/object.

Furthermore, the wiring of a network often contains information about the system. Considering, for instance, a friendship network, it is common that your friend's friend is also your friend. This phenomenon can be measured through the clustering coefficient of the friendship network (Wang and Chen, 2003). Another example is an especially uneven connectivity pattern. If we study for example air transportation networks (Guimerà et al., 2005; Xu and Harriss, 2008), chemical networks (Bishop et al., 2006; Jacob and Lapkin, 2018; Weber et al., 2019), or the internet (Page et al., 1999; Wang and Chen, 2003), we will find a
Sustainable development goals workshop 
IJSHE 22,8

relatively small set of key elements of the system. The most simplistic way of looking at the patterns is by the degree of vertices, i.e. the number of edges at every vertex, and its distribution. There exist many more properties of graphs which are used to understand a network and its complexity. For a more comprehensive view, we refer the reader to further literature (Barabási, 2016; Boccaletti et al., 2006).

Network science offers a common language to deal with complexity, and it provides both mathematical formalisms and data-driven computational tools to quantify features and behaviours of a complex system (Barabási, 2016). Understanding concepts of networks has become a relevant part in people's everyday life, which renders education for it even more essential (Sayama et al., 2017).

\subsection{Sustainability and sustainable development goals}

The well-known concept of sustainable development formulated in Our Common Future states that "sustainable development is development that meets the needs of the present without compromising the ability of future generations to meet their own needs" (World Commission on Environment and Development, 1987). However, contradictions between economic growth and ecological conservation, power relations supporting unsustainable development (Sneddon et al., 2006), and the difficulties that long time horizons and inter-generational moral bring about have been noted critically (Pearce and Atkinson, 1998). Dictionary definitions state that sustainability describes activities/actions that can be sustained. Such definitions are considered problematic concerning the time-frame over which systems are to be sustained and also ecosystems abilities to adapt to changes and therewith sustain (Johnston et al., 2007). It appears to be common knowledge that the term "sustainability" lacks a clear definition, i.e. more than 300 definitions of sustainability have been estimated in 2007 (Johnston et al., 2007), and is often interpreted in especially favourable ways, possibly leading to an abuse of the word (Morelli, 2011). The problem is not novel though; in 1994, Allen and Hoekstra argued that "[...] sustainability is an immature notion. It conjures up different images for each environmental scientist and manager, although there is a common, general understanding" (Allen and Hoekstra, 1994). Different perspectives from different societies, the importance of spatial and temporal scales, as well as social, ecological and economic perspectives, have been acknowledged by Brown et al. (1987) in the same year as Our Common Future was published.

Considering representations of sustainability, we recognise a useful simplification of the concept of sustainability in the Three Pillar Model of Sustainability where we rediscover the previously mentioned perspectives: Economy - Society - Environment, indicating that sustainable solution must advance performance in the three pillars. A typical representation shows interlinking circles, while further forms of representation are actual pillars, or a concentric approach (Purvis et al., 2019). This indicates that there are still various understandings of the relationships between the fields. Almost all societies value a combination of economic development, environmental awareness and social inclusion, while there exist different objectives in the global context but also within a society (Sachs, 2012). The conceptions of sustainability and sustainable development are complex and not unambiguously representable or agreeable; nevertheless, they are the guidelines for our future (Sachs, 2012) and the basis for current policymaking.

The major international guidelines for sustainable policymaking are the United Nations SDGs, which were articulated in the UN 2030 Agenda for Sustainable Development and aim to address systematic barriers to sustainable development. They are a successor of the Millennium Development Goals (MDGs) and are seen as an important step forwards by many (Costanza et al., 2016; Vladimirova and Le Blanc, 2015, 2016). However, Cummings et $a l$. argue that the SDGs fail in taking local knowledge and individual backgrounds into 
account (Cummings et al., 2018). On the contrary, Swain reasons that the goals, in particular their measurability and monitoring, are governed by each nation individually, making an effective execution difficult (Swain, 2018). Additionally, the underlying neoliberalism, on which basis the MDGs and SDGs were built, is seen not to be suitable for sustainable development after all (Briant Carant, 2017).

There are 17 SDGs with 169 sub-targets, which are monitored through a set of global indicators complemented by indicators on the regional and national level (Desa, 2016). The goals are designed as an integrated policy framework, functioning as a whole rather than isolated targets (King, 2017). They apply to developing as well as developed countries and are thought to spark systematic change on local and global levels by the year 2030 (Axon and James, 2018; Costanza et al., 2016). The goals are outlined in Figure 1.

To guide action and to reach a more sustainable society by 2030, the scientific community stresses that a better understanding of the connections between targets is necessary (Kroll et al., 2019; Lu et al., 2015).

Implicit in the SDG logic is that the goals depend on each other - but no one has specified exactly how (Nilsson et al., 2016).

Vladimirova and Le Blanc state that the recognition of interdependencies, trade-offs, synergies and their implementation within the goals is crucial (Vladimirova and Le Blanc, $2015,2016)$. Constanza et al. discuss the lack of clear guidance within the goals as well as the deficiency of explanation about the connection between the goals (Costanza et al., 2016). According to Le Blanc, the negative effects of insufficient understanding of the connections between the goals have already lead, among others, to incoherent policies (Le Blanc, 2015) and Spaiser et al. come to the conclusion that the SDG agenda will fail if inconsistencies remain unaddressed (Spaiser et al., 2017). Pradhan et al. criticises that a systematic and datadriven evaluation of the connections between the SDGs is lacking (Pradhan et al., 2017).

Recent works have investigated clusters of SDGs (Le Blanc, 2015; Costanza et al., 2016; Stockholm Resilience Centre, 2017) material balances connecting the goals (Mahaffy et al., 2019), the directions/weights/or other attributes of the interactions (Le Blanc, 2015;

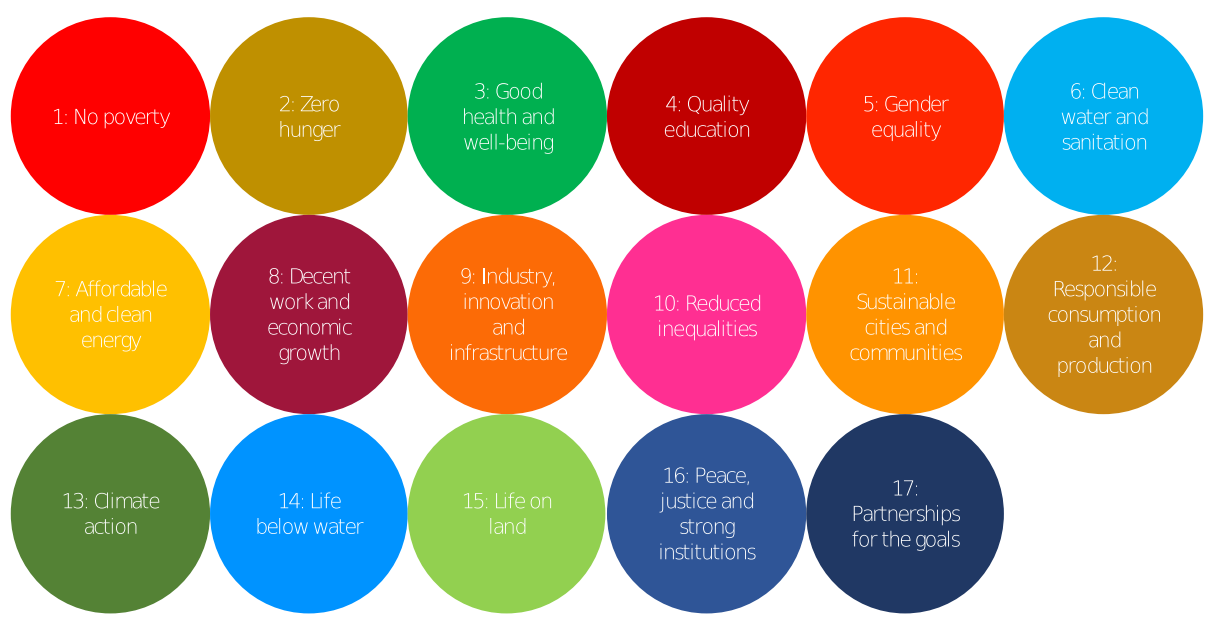

Source: Desa (2016), United Nations Department of Public Information (2020)
Sustainable development goals workshop
Figure 1.

An outline of the

United Nations

sustainable

development goals based on the Agenda 
IJSHE 22,8

Vladimirova and Le Blanc, 2015, 2016), most connected goals (Le Blanc, 2015; Vladimirova and Le Blanc, 2015) as well as areas of low connectivity (Vladimirova and Le Blanc, 2015). Nerini et al. focused on the synergies and trade-offs concerning SDG7 (Nerini et al., 2018), while Vladimirova and Le Blanc focused on connections of SDG4 (Vladimirova and Le Blanc, 2015). For a more comprehensive view on studies about SDG interdependencies, we suggest the reader further literature (Breuer et al., 2019).

Despite mentioned criticism (Briant Carant, 2017; Cummings et al., 2018; Swain, 2018), we recognise SDGs as broadly agreed global sustainability dimensions and the network of SDGs as an applicable case study, as it outlines connections between the dimensions, is of high relevance, and offers a relatively small network size to be suitable as a teaching example.

\section{Workshop development}

In this section, we reason about the educational paradigm and content to design the sustainability workshop. Sustainability workshops based on peer-learning are applied for diverse sets of target groups and sustainability aspects in Germany, e.g. the student-led project Wellenschlagen at the University of Kiel[1], regional peer-to-peer learning groups to develop, finance and implement renewable energy and climate action plans[2], and the UNECE Environmental Performance Review Program focusing on SDGs in Eastern Europe [3]. To the best of our knowledge, the complex systems approach has not been a focus yet.

\subsection{Educational paradigms}

According to Orr (1994), many of the worlds' problems are not due to a lack of education but rather results from an education which "fragments instead of unifies" and which "separates feelings from intellect" (Orr, 1994). The education sector has become governed by neoliberalism, as some state (Huckle and Wals, 2015; Jickling and Wals, 2008; Sterling, 2017), with a global "education industry" of $\$ 5.0 \mathrm{tn}$ and its main purpose to deploy a certain workforce (Sterling, 2017). In the neoliberal context, "the default pedagogy is "delivery" by experts (and) values, ethics, emotions, and intuition have little or no place in education" (Sterling, 2017).

Sustainability concepts are difficult to comprehend at present and will most likely evolve over time (Jickling and Wals, 2008), rendering it impossible for educators to decide on the "one" solution. Rather, education should be the mean to create true democracy and emancipation, by supporting learners to develop their potential in a joint manner for collective reshaping of the future (Huckle, 1991). Furthermore, education should provide a platform for feelings, values and ethics. As Jickling states (Jickling, 2017):

[... ] the success of the 2030 agenda will likely fail if nation states and their citizens do not care - about poverty, hunger, equity, or more-than-the-human world. [ . . . the [ . . ] point about caring is prescient.

Transformative learning, which Sterling characterises as deeply touching and with the potential to change deep levels of values and beliefs, answers raised questions (Huckle and Wals, 2015; Lotz-Sisitka et al., 2015; Sterling, 2010). Huckle and Wals describe necessary dimensions for ecopedagogy to strive for transformative ESD (Huckle and Wals, 2015), while Lotz-Sisitka et al. outline four streams of transformative learning for disruptive capacity-building instead of resilience (Lotz-Sisitka et al., 2015). Transformative learning may be fostered through a combination of ESD paradigms (Sterling, 2010). For the full outline of the paradigms, we refer the reader to (Sterling, 2010).

First, from instrumental ESD, Sterling advises to adapt the recognition of urgency, and the need for content especially on resilience theory and systems concepts (Sterling, 2010). Our workshop focuses on the delivery of content on systems concepts. Most importantly from intrinsic ESD, adapting the need for critically aware, reflexive and autonomous leaders 
is key (Sterling, 2010). Our workshop provides a safe space for reflections and autonomous work tasks. Thirdly, from the concepts of resilient learner and development theory, Sterling suggests that individual resilience and adaptability should be valued as essential qualities (Sterling, 2010). We confront learners with constantly changing situations and the failure of parts of their systems throughout the workshop. Ultimately, Sterling regards social learning and resilience theory and advises using the ideas of participative learning and dynamic systems concepts (Sterling, 2010). Our workshop touches on dynamic systems and is throughout based on peer-learning.

\subsection{Workshop content}

The extracurricular workshop covered $15 \mathrm{~h}$ with a group of 17 participants and took place in Germany. The participants were from varying disciplines and stages of undergraduate and graduate courses, as well as professionals from different sectors of industries.

During the workshop, each participant presents a methodological concept of network theory and one SDG, which they prepared prior to the workshop. Discussions and/or practical tasks follow each presentation, making it a problem-based workshop to enhance understanding and increase discussions. Walking through the network methodology, the different hypotheses about the network of SDGs evolve, are questioned and further redefined. Figure 2 illustrates some possibilities of the connectivity between the SDGs and is an example of possible workshop outcomes.

The workshop consists of four main topics. First, an introduction to sustainability and its relation to complexity is given; second, concepts of network science as a tool to work with complexity are discussed; third, questions about sustainability are posed and worked on from a network perspective; and fourth, a comparison to other works is discussed and reflections about the workshop are gathered and exchanged (see the slide deck in the Electronic Supplementary Information).

Session 1a: Introduction to sustainability and sustainable development

Participants are asked to present common concepts of sustainability, such as the sustainability definition from Our Common Future, the Three Pillar Model, and to discuss system thinking in the context of sustainability. The discussion focuses on critical opinions about the models and is followed by various short presentations to introduce previously assigned SDGs.

\section{Session 1b: Sustainability and complexity}

The workshop session explores the connection between sustainability and complexity from different perspectives. The participants review two scientific articles and discuss the authors' views. The first article introduces complexity as a human strategy of problemsolving and elucidates its historical context (Tainter, 2006). Problem-solving institutions are characterised with three different outcomes: resilience due to simplification, collapse and continuity through energy subsidises, which allow for growing complexity. Sustainability, as in to sustain, is not a rather passive consequence of consuming less, but an active condition of problem-solving (Tainter, 2006). The second article describes both social and natural systems through a complex panarchical structure of adaptive cycles and explains phases of creation and destruction in the model (Holling, 2001). The adaptive cycles exist on different levels, in nature, e.g. from single plants to entire landscapes, and in human systems, e.g. from individual decisions to law constitution and culture. Changes may propagate through the levels (Holling, 2001).

Session 2a: Introduction to network science

The historic Königsberger Bridge Problem and Leonhard Euler's solution are presented, as well as two fundamental concepts of network science: edges and nodes. All participants are asked to represent SDGs as a first version of a network, initiating discussions on types of
Sustainable development goals workshop 
IJSHE

22,8

32

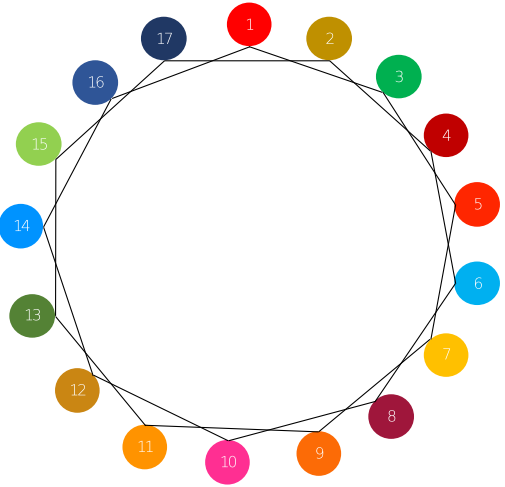

(a)

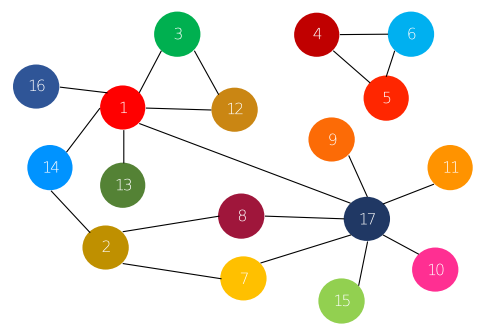

(c)

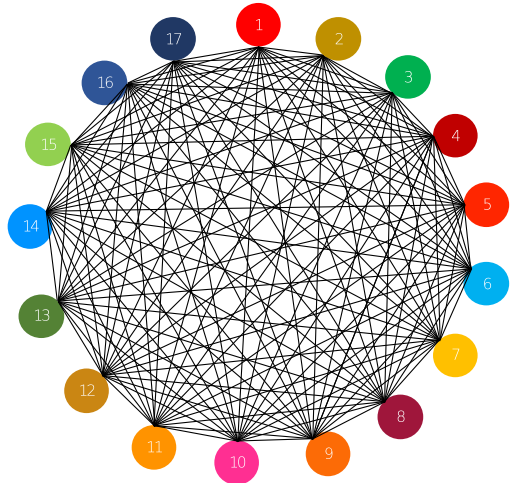

(b)

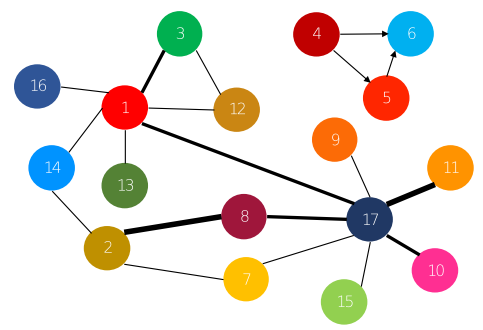

(d)

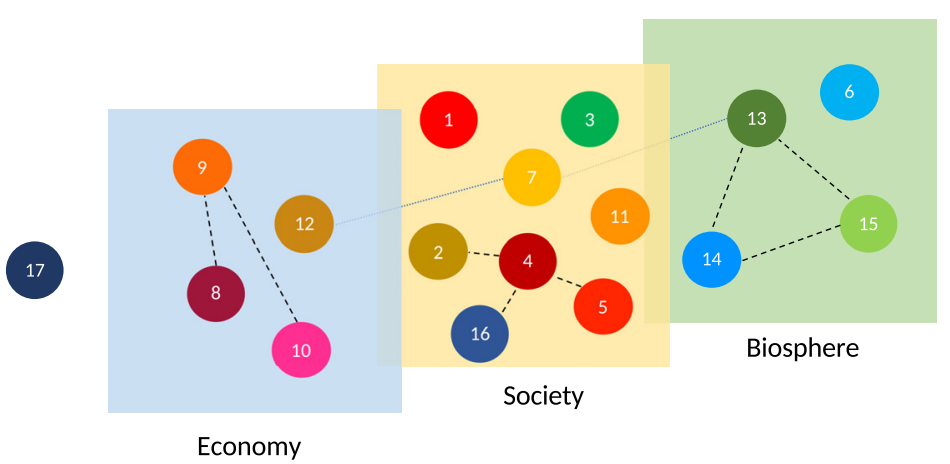

(e)

Notes: Note that links are drawn arbitrary with the sole purpose to exemplify the network methodologies: (a) and (b) show regular networks, (c) shows an irregular network structure with hub nodes and graph components, whereas (d) illustrates weights for more important interactions and directed links for unilateral interactions.

Figure 2.

Network

representations of SDGs
In (e) we show the SDGs in different layers (here, according to the Stockholm resilience model (Stockholm Resilience Centre, 2017), which allow for interand intralayer linkage 
interactions. A further presentation explains directions and weights of edges, the concept of degrees and neighbours, and shows various examples of applications of network science. The main considerations are focused on the type of networks and attributes of edges required to represent interactions between SDGs.

Session 2b: More about network science

Methodological inputs in this session explain the adjacency matrix and global network metrics, such as size, density, clustering coefficient, the number of components and the network diameter. Participants are asked to evaluate their network representation and identify some of the metrics. Furthermore, the group is asked to find out if the network could be clustered or broken into different components. Sub-groups based on links or based on content are discussed.

Session 2c: Network types

Participants explain and discuss the concepts of degree and average distance distribution functions. Their knowledge evolves from Erdös-Rényi graphs and regular graphs to scale-free graphs, preferential attachment and small-world graphs. Here, the importance of the underlying network structures becomes evident and participants start to discuss wiring of the SDG network. Additionally, more special network forms, such as multipartite or multilayer networks, are reviewed. With the introduction of these network forms, participants are allowed to include additional information, for example through a second layer or different node types, into the SDG network, leading to a discussion about the desired level of simplification.

\section{Session 2d: Measuring the importance of nodes}

A node's significance is often examined by its centrality in the network structure. Participants are asked to relate centralities of SDGs (incoming links, outgoing links and total amount of links) back to the political framework. What are the implications of a high or a low centrality of SDGs within the framework? Furthermore, we focus on interesting substructures in the network, such as loops and circular structures and their utilisation.

Session 3a: Measuring sustainability through network science

This session focuses on work about the utilisation of network metrics to assess the sustainability of socio-ecological systems (Gonzalès and Parrott, 2012). In their work, Gonzalès and Parrott hypothesis that a sustainable system is a resilient system and that resilience may be described through the robustness of a network. A variety of network metrics and how they can influence robustness are discussed (Gonzalès and Parrott, 2012). As a practical exercise, participants are confronted with hypothetical scenarios about the deletion of specific nodes in their network and have to investigate the robustness of their networks regarding potential node failures.

Session 3b: Practical session about trade-offs

Up to this point, the focus of all investigations had been on positive effects of influence and synergies. In this additional session, participants are asked to conceptualise an additional network describing trade-off effects between SDGs. Can fulfilling certain goals lead to a problematic situation for other goals? Similar questions as previously discussed are posed, e.g. about highly connected nodes, clusters and loops in the trade-off network.

Session 3c: Simulations in networks

We focus on a relatively simple simulation framework in which the group can work without programming. Petri Nets as a modelling tool are explained, discussed and introduced with the aid of online software. Participants are asked to construct an SDG network as a Petri Net and follow the synergy or trade-off flows through the network.

Session 4a: Final comparison

This session aims to allow the participants to compare their models and insights with approaches from the literature. The study of Le Blanc performed very similar investigations
Sustainable development goals workshop 
IJSHE 22,8

of the connectedness of SDGs and found areas with high and low connectedness (Le Blanc, 2015). Pradhan et al. investigated synergies and trade-offs within the SDGs based on SDG indicator data (Pradhan et al., 2017). Participants can compare the links drawn in the literature with their own understanding developed throughout this workshop. We also used the Stockholm resilience model for comparison (Stockholm Resilience Centre, 2017).

Session 4b: Reflection

The last session is used for reflections about the teaching method, the knowledge gained and network science as a tool to handle sustainability problems.

In conclusion, Network science was chosen to provide skills on systems theory and to provide a common language for all disciplines. Building links between dimensions of sustainability fosters a systems view and follows Sterlings argument to go against the conventional reductionist technique (Sterling, 2004). Links between SDGs (directions and weights) are applied to describe and quantify relationships between dimensions. The network density and the degree distribution allow to inspect the connectivity of the political action plan. Node centralities (hubs) show the importance and influence of certain dimensions. Network science elucidates well and loosely embedded SDGs and helps to quantify their relationships. With regard to wicked problems, network science helps to investigate various present and future scenarios. We can inspect possible outcomes and contradictions, which helps to work with ill-defined problems. Last, but not least, the complex systems approach answers a part of the ESD dilemma as it familiarises students with complex interactions, dynamic changes and systems thinking.

\section{Reflection}

We present a qualitative evaluation of the covered content (Section 4.1) and teaching method (Section 4.2), as well as the limitations of the workshop (Section 4.3). Quotes of participants are included in this section.

\subsection{Content}

We noticed most criticism from the group about the presented literature on complexity and sustainability (Session 1b). First, the group discussed the framework of social complexity and sustainability as well as the concept of affording sustainability. They questioned the lessons learned about sustainability in human systems formulated by Tainter (2006) and suggested that the understanding of sustainability in human systems at present might have changed. Second, Hollings concept of the adaptive cycle and the panarchie was critically discussed by the group, in particular, the communication between different levels was argued to be idealistic (Holling, 2001).

Concerning the SDGs, the participants focused on the sub-goals to define an interaction. The task of building clusters or graph components was controversial as participants experienced high connectivity of the SDG framework (Session 2b). After the introduction of the various types of networks (Session 2c), the participants noticed the growing complexity. The discussion formed the opinion that a simplistic directed network is most suited for now. In Session 2d, significant progress was made as participants found uneven linkages between goals, resulting in hub nodes, based on either their in-degree or out-degree. Hence, some goals were more influential while others were more receiving. This finding was later on compared with Le Blanc's thorough investigation (Le Blanc, 2015). Further discoveries included loops in the graph, e.g. better education leads to even better education, and cycles, where improvements in one goal might lead to an improvement in others, which ultimately influences the initial goal again. The environmental subsystems of SDG13, SDG14 and SDG15 was discussed in this regard. 
The uneven linkages were of importance for the robustness of the system (Session 3a); when hub nodes were removed, the network structure became fragile. The evaluation of network structures, e.g. which are robust concerning node failure, or which allow for efficient flows in the network, was discussed on the basis of the work by Gonzalèz and Parrott (Gonzalès and Parrott, 2012). In Session 3b, an active approach was made to better understand the trade-offs between certain goals. A link from A to B only exists if A may potentially be harmful for B. Participants discovered uneven linkages and linkage directions. While some SDGs were potentially more harmful, others were found to be more in danger and dependent on the success of others.

It (Network Science) made me realise that the fulfilment of some SDGs depends on the realisation of others, but that proceeding in one SDG could also negatively impact the progress of another one.

Moreover, network theory also points out the subjectivity in mapping these interlinkages among the goals. Not only in existing literature (e.g. Le Blanc, 2015) but also in our workshop, the approaches to map the complexity and the relations within the SDGs differed largely.

The comparison of outcomes reached by the participants with those available in the literature leads to two conclusions: The approximate clustering of the Stockholm Resilience model (Stockholm Resilience Centre, 2017) was not found in the workshop as the use of network science led to the discovery of many links between goals of different pillars. However, each group could recognise some of their considerations in the work by Pradhan and co-workers (Pradhan et al., 2017). This indicates that the workshop has enabled participants to compare their understanding of a topic previously novel to them with international experts in the field in only three days.

Finally, the group concluded that network science was an appropriate tool to investigate the integration of SDGs as it allowed for communication between the disciplines. However, they saw limitations when it came to simplification of problems:

Using network science made it possible to see through the complexity of the connections between the SDGs and reduce it to a manageable level.

Yet, and the workshop has shown this as well, there are limits to the extent a network can reproduce the plethora of factors [...] in the actual world. Therefore, network science is not the one-size-fits-all solution to 'simply' calculating how to solve the obstacles to successful SDG implementation.

Additionally, having learned much about the single goals and their sub-targets as well as about the integrated policy framework was positively highlighted by the participants.

This new perspective helped me to understand [...] the role they (SDGs) play in promoting sustainability.

\subsection{Educational framework}

It was noted critically that being an advocate of one specific SDG (Session 1a) brings about bias into the discussion and that the group size was too large for practical tasks with the entire group. Shortly outlining every SDG required much time, and we suggest to revise the format for this task, e.g. limiting it to one minute or three key phrases per SDG. Alternatively, a more active atmosphere could be created by discussing them in smaller groups. We recommend to separate the group into two or more subgroups and finish with respectively two or more network representations as this showed to facilitate group dynamics and prevent SDG bias. Furthermore, results were seen with caution as the group 
IJSHE

22,8

viewed the problem from a very homogenous perspective, neglecting cultural differences and diverse global consequences.

Besides this, the feedback was mainly positive. The reflection part revealed that the workshop's content has a good mixture of theory and practical tasks.

$[\ldots]$ (this) embeds [ . . ] learnings much better in [ . . ] memory and improves the learning curve.

The challenge of having to explain methodological input to an interdisciplinary group was also positively noted. The learning itself might be seen as deeper and more integrative. The variety of formats, from whole group discussions, to smaller groups syndicate sessions and presentations, as well as the use of diverse materials, was positively recognised. Interdisciplinary learning as well as critical thinking were enabled:

I really appreciated both the team-work and the interdisciplinary approaches as it pushed me to question and explain my point of view.

Based on expectations as well as reflections, it was noticeable that knowledge about network science and SDGs was both desired and attained.

\subsection{Workshop limitations}

The workshop was limited to one sustainability case study; the connectedness of SDGs and one tool from complexity science; network science. We understand that every sustainability problem bears unique challenges; hence, the approach may be more suitable for some than for others. Furthermore, we focused on basic network metrics, which bring about a rather static picture of the system. We recognise that a more holistic assessment of sustainable development requires dynamic concepts and associations of flows within the network. We touched only shortly on dynamics in the network through the notion of Petri Nets. Ultimately, the evaluation of the workshop is based on qualitative feedback from interactions with the participants. If it were repeated for a larger group of participants, a quantitative evaluation would be desirable.

\section{Conclusions}

Sustainability education is a challenging field as educators cannot know what exact skills are required for solving both current and future sustainability challenges. In this work, we have suggested one possibility of handling sustainability problems, by approaching them with a complex systems approach: network science, see Figure 3.

Network science supports the highly relevant systems view, stressed in the ESD literature. We provided an educational framework which embedded network science in a peer-based, problem-oriented and transformative learning approach. We found that the workshop familiarises non-experts from different fields to jointly work with complex systems, which is required for wicked problems, in a short amount of time. The positive resonance of the workshop was more than expected and highlights that both content and teaching approach were well received by the learners. The study is limited to a purely qualitative assessment of the teaching method and content on mainly static network metrics. We introduced network science for sustainable education as a novel approach, and we strongly recommend to educational institutions, corporate trainings, or other stakeholders in the education landscape to integrate similar concepts, as it is a widely applicable and easily reproducible, yet highly effective teaching approach. Furthermore, this work highlights the importance of complex systems approaches for sustainable development research. 


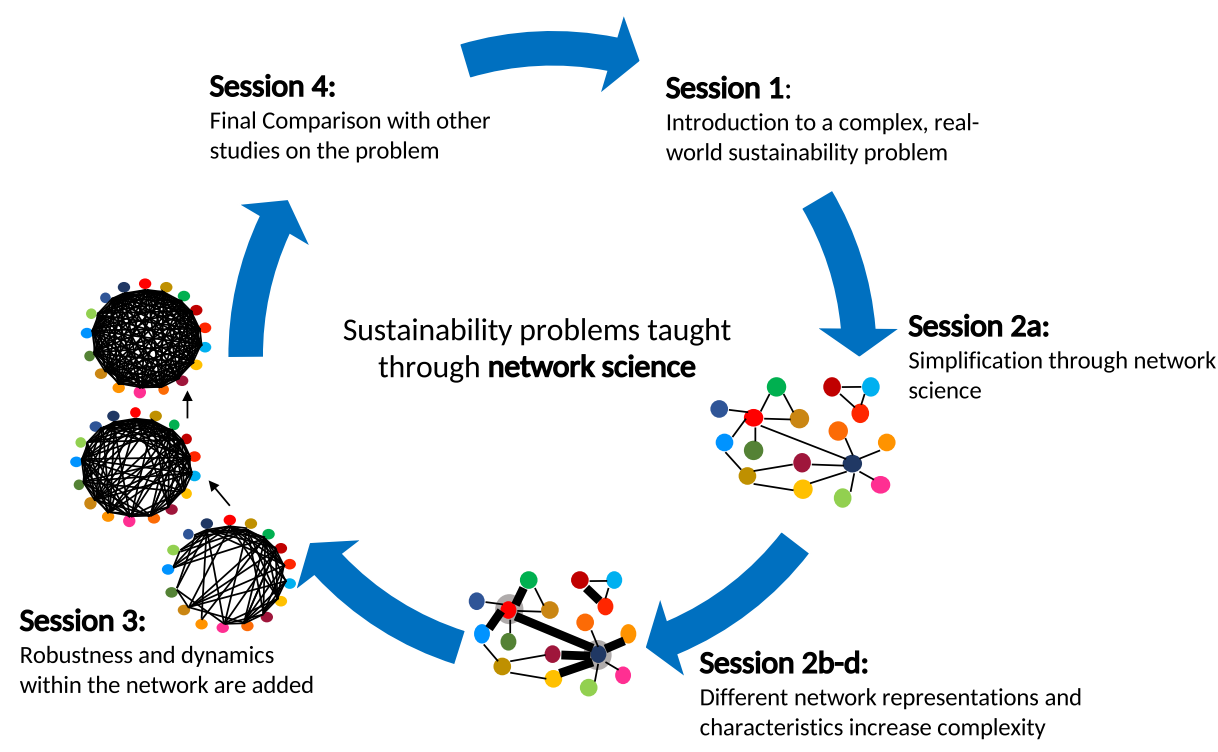

Notes: We first simplify a complex sustainability problem through its main interactions and gradually build-up complexity by introducing new network methodologies

Figure 3.

Scheme of the workshop sessions

\section{Notes}

1. Find project details: www.wellenschlagen.org/seminar

2. Find project details: https://h2020prospect.eu

3. Find project details: www.umweltbundesamt.de/sites/default/files/medien/1411/beratungshilfe/info_5190_en_0.pdf

\section{References}

Albareda-Tiana, S., Vidal-Raméntol, S., Pujol-Valls, M. and Fernández-Morilla, M. (2018), "Holistic approaches to develop sustainability and research competencies in pre-service teacher training", Sustainability, Vol. 10 No. 10, p. 3698.

Allen, T.F.H. and Hoekstra, T.W. (1994), "Towards a definition of sustainability", in Covington, WW. And DeBano, LF. (Eds), Sustainable Ecological Systems: Implementing an Ecological Approach to Land Management, Gen. Tech. Rep. RM-247, US Department of Agriculture, Forest Service, Rocky Mountain Forest and Range Expe, Fort Collins, CO, pp. 98-107.

Allen-Gil, S., Walker, L., Thomas, G., Shevory, T. and Elan, S. (2005), "Forming a community partnership to enhance education in sustainability", International Journal of Sustainability in Higher Education, Vol. 6 No. 4, pp. 392-402.

Axon, S. and James, D. (2018), "The UN sustainable development goals: how can sustainable chemistry contribute? A view from the chemical industry", Current Opinion in Green and Sustainable Chemistry, Vol. 13, pp. 140-145.

Barabási, A.-L. (2016), Network Science, Cambridge University Press, Cambridge.

Barabási, A.-L. and Bonabeau, E. (2003), “Scale-free networks”, Scientific American, Vol. 288 No. 5, pp. 60-69. 
IJSHE 22,8

Barnes, J.A. and Harary, F. (1983), "Graph theory in network analysis”, Social Networks, Vol. 5 No. 2, pp. 235-244.

Bartels, K.A. and Parker, K.A. (Eds) (2012), Teaching Sustainability/Teaching Sustainably, Stylus Publishing, Sterling, VA.

Bauer, M., Bormann, I., Kummer, B., Niedlich, S. and Rieckmann, M. (2018), "Sustainability governance at universities: using a governance equalizer as a research heuristic", Higher Education Policy, Vol. 31 No. 4, pp. 491-511.

Bishop, K.J.M., Klajn, R. and Grzybowski, B.A. (2006), "The core and most useful molecules in organic chemistry", Angewandte Chemie International Edition, Vol. 45 No. 32, pp. 5348-5354.

Boccaletti, S., Latora, V., Moreno, Y., Chavez, M. and Hwang, D.U. (2006), "Complex networks: structure and dynamics", Physics Reports, Vol. 424 Nos 4/5, pp. 175-308.

Börner, K., Sanyal, S. and Vespignani, A. (2007), "Network science”, Annual Review of Information Science and Technology, Vol. 41 No. 1, pp. 537-607.

Bourn, D. Hunt, F. and Bamber, P. (2017), "A review of education for sustainable development and global citizenship education in teacher education".

Breuer, A., Janetschek, H. and Malerba, D. (2019), "Translating sustainable development goal (SDG) interdependencies into policy advice", Sustainability, Vol. 11 No. 7, pp. 2092-2112.

Briant Carant, J. (2017), "Unheard voices: a critical discourse analysis of the millennium development goals' evolution into the sustainable development goals”, Third World Quarterly, Vol. 38 No. 1, pp. $16-41$.

Brown, B.J., Hanson, M.E., Liverman, D.M. and Merideth, R.W. (1987), “Global sustainability: toward definition”, Environmental Management, Vol. 11 No. 6, pp. 713-719.

Brown, V.A., Harris, J.A. and Russell, J.Y. (Eds) (2010), Tackling Wicked Problems through the Transdisciplinary Imagination, Earthscan.

Costanza, R., Daly, L., Fioramonti, L., Giovannini, E., Kubiszewski, I., Mortensen, L.F., Pickett, K.E., Ragnarsdottir, K.V., De Vogli, R. and Wilkinson, R. (2016), "Modelling and measuring sustainable wellbeing in connection with the UN sustainable development goals", Ecological Economics, Vol. 130, pp. 350-355.

Cummings, S., Regeer, B., de Haan, L., Zweekhorst, M. and Bunders, J. (2018), "Critical discourse analysis of perspectives on knowledge and the knowledge society within the sustainable development goals", Development Policy Review, Vol. 36 No. 6, pp. 727-742.

Davidson, C.I., Hendrickson, C.T., Matthews, H.S., Bridges, M.W., Allen, D.T., Murphy, C.F., Allenby, B. R., et al. (2010), "Preparing future engineers for challenges of the 21st century: sustainable engineering", Journal of Cleaner Production, Vol. 18 No. 7, pp. 698-701.

Derrible, S. and Kennedy, C. (2011), "Applications of graph theory and network science to transit network design”, Transport Reviews, Vol. 31 No. 4, pp. 495-519.

Desa, U.N. (2016), "Transforming our world: the 2030 agenda for sustainable development".

Fenner, R.A., Ainger, C.M., Cruickshank, H.J. and Guthrie, P.M. (2005), "Embedding sustainable development at Cambridge University engineering department", International Journal of Sustainability in Higher Education, Vol. 6 No. 3, pp. 229-241.

Filho, W.L. and Dahms, L.-M. (2018), "Incorporating sustainable development issues in teaching practice", Implementing Sustainability in the Curriculum of Universities, World Sustainability Series, Springer, Cham, pp. 323-330.

Gonzalès, R. and Parrott, L. (2012), "Network theory in the assessment of the sustainability of socialecological systems", Geography Compass, Vol. 6 No. 2, pp. 76-88.

Guimerà, R., Mossa, S., Turtschi, A. and Amaral, L.A.N. (2005), "The worldwide air transportation network: anomalous centrality, community structure, and cities' global roles", Proceedings of the National Academy of Sciences of Sciences, Vol. 102 No. 22, pp. 7794-7799. 
Hermann, R.R. and Bossle, M.B. (2020), "Bringing an entrepreneurial focus to sustainability education: a teaching framework based on content analysis", Journal of Cleaner Production, Vol. 246, pp. 119038

Hoffmann, T. and Siege, H. (2018), "What is education for sustainable development (ESD)?", Human Development, Vol. 1 No. 8, pp. 1-6.

Sustainable development goals workshop

Holling, C.S. (2001), "Understanding complexity of economic, ecological, and social systems", Ecosystems, Vol. 4 No. 5, pp. 390-405.

Huckle, J. (1991), "Education for sustainability: assessing pathways to the future", Australian Journal of Environmental Education, Vol. 7, pp. 43-62.

Huckle, J. and Wals, A.E.J. (2015), "The UN decade of education for sustainable development: business as usual in the end", Environmental Education Research, Vol. 21 No. 3, pp. 491-505.

Iwaniec, D.M., Childers, D.L., VanLehn, K. and Wiek, A. (2014), "Studying, teaching and applying sustainability visions using systems modeling", Sustainability, Vol. 6 No. 7, pp. $4452-4469$.

Jacob, P.M. and Lapkin, A. (2018), "Statistics of the network of organic chemistry", Reaction Chemistry and Engineering, Vol. 3 No. 1, pp. 102-118.

Jickling, B. (2017), "Education revisited: creating environmental experiences that are held, felt, and disruptive", in Jickling, B. and Sterling, S. (Eds.), Post Sustainability and Environmental Education: Remaking the Future for Education, Palgrave Macmillan, Cham, pp. 15-30.

Jickling, B. and Wals, A.E.J. (2008), "Globalization and environmental education: looking beyond sustainable development”, Journal of Curriculum Studies, Vol. 40 No. 1, pp. 1-21.

Johnston, P., Everard, M., Santillo, D. and Robèrt, K. (2007), "Reclaiming the definition of sustainability", Environmental Science and Pollution Research - International, Vol. 14 No. 1, pp. 60-66.

King, K. (2017), "Lost in translation? The challenge of translating the global education goal and targets into global indicators", Compare: A Journal of Comparative and International Education, Vol. 47 No. 6, pp. 801-817.

Kroll, C., Warchold, A. and Pradhan, P. (2019), "Sustainable development goals (SDGs): are we successful in turning trade-offs into synergies?", Palgrave Communications, Vol. 5 No. 1, pp. 1-11.

Le Blanc, D. (2015), "Towards integration at last? The sustainable development goals as a network of targets", Sustainable Development, Vol. 23 No. 3, pp. 176-187.

Lotz-Sisitka, H., Wals, A.E.J., Kronlid, D. and McGarry, D. (2015), "Transformative, transgressive social learning: rethinking higher education pedagogy in times of systemic global dysfunction", Current Opinion in Environmental Sustainability, Vol. 16, pp. 73-80.

Lozano, R., Barreiro-Gen, M., Lozano, F.J. and Sammalisto, K. (2019), "Teaching sustainability in European higher education institutions: assessing the connections between competences and pedagogical approaches", Sustainability, Vol. 11 No. 6, pp. 1602

Lu, Y., Nakicenovic, N., Visbeck, M. and Stevance, A.-S. (2015), "Five priorities for the UN sustainable development goals", Nature, Vol. 520 No. 7548, pp. 432-433.

Mahaffy, P.G., Matlin, S.A., Holme, T.A. and MacKellar, J. (2019), "Systems thinking for education about the molecular basis of sustainability", Nature Sustainability, Vol. 2 No. 5, pp. 362-370.

Morelli, J. (2011), "Environmental sustainability: a definition for environmental professionals", Journal of Environmental Sustainability, Vol. 1 No. 1, pp. 1-10.

Mulà, I., Tilbury, D., Ryan, A., Mader, M., Dlouhá, J., Mader, C., Benayas, J., et al. (2017), “Catalysing change in higher education for sustainable development: a review of professional development initiatives for university educators", International Journal of Sustainability in Higher Education, Vol. 18 No. 5, pp. 798-820.

Nerini, F.F., Tomei, J., To, L.S., Bisaga, I., Parikh, P., Black, M., Borrion, A., et al. (2018), "Mapping synergies and trade-offs between energy and the sustainable development goals", Nature Energy, Vol. 3 No. 1, pp. 10-15. 
IJSHE 22,8

Nilsson, M., Griggs, D. and Visbeck, M. (2016), "Policy: map the interactions between sustainable development goals”, Nature, Vol. 534 No. 7607, pp. 320-322.

Orr, D. (1994), Earth in Mind - on Education, Environment and the Human Prospect, Island Press, Washington, DC.

Page, L. Brin, S. Motwani, R. and Winograd, T. (1999), "The PageRank citation ranking: bringing order to the web", Stanford InfoLab.

Pappas, E., Pierrakos, O. and Nagel, R. (2013), "Using bloom's taxonomy to teach sustainability in multiple contexts", Journal of Cleaner Production, Vol. 48, pp. 54-64.

Pearce, D. and Atkinson, G. (1998), "The concept of sustainable development: an evaluation of its usefulness ten years after Brundtland", Swiss Journal of Economics and Statistics, Vol. 134 No. 3, pp. 251-269.

Perdan, S., Azapagic, A. and Clift, R. (2000), "Teaching sustainable development to engineering students", International Journal of Sustainability in Higher Education, Vol. 1 No. 3, pp. 267-279.

Pradhan, P., Costa, L., Rybski, D., Lucht, W. and Kropp, J.P. (2017), “A systematic study of sustainable development goal (SDG) interactions”, Earth's Future, Vol. 5 No. 11, pp. 1169-1179.

Purvis, B., Mao, Y. and Robinson, D. (2019), "Three pillars of sustainability: in search of conceptual origins”, Sustainability Science, Vol. 14 No. 3, pp. 681-695.

Rittel, H.W.J. and Webber, M.M. (1973), "Dilemmas in a general theory of planning", Policy Sciences, Vol. 4 No. 2, pp. 155-169.

Sachs, J.D. (2012), "From millennium development goals to sustainable development goals", The Lancet, Vol. 379 No. 9832, pp. 2206-2211.

Sayama, H., Cramer, C., Sheetz, L. and Uzzo, S. (2017), "NetSciEd: network science and education for the interconnected world”, ArXiv Preprint ArXiv:1706.00115,

Seager, T., Selinger, E. and Wiek, A. (2012), "Sustainable engineering science for resolving wicked problems", Journal of Agricultural and Environmental Ethics, Vol. 25 No. 4, pp. 467-484.

Seatter, C.S. and Ceulemans, K. (2017), "Teaching sustainability in higher education: pedagogical styles that make a difference", Canadian Journal of Higher Education, Vol. 47 No. 2, pp. 47-70.

Sneddon, C., Howarth, R.B. and Norgaard, R.B. (2006), "Sustainable development in a post-Brundtland world”, Ecological Economics, Vol. 57 No. 2, pp. 253-268.

Spaiser, V., Ranganathan, S., Swain, R.B. and Sumpter, D.J.T. (2017), "The sustainable development oxymoron: quantifying and modelling the incompatibility of sustainable development goals", International Journal of Sustainable Development and World Ecology, Vol. 24 No. 6, pp. 457-470.

Sterling, S. (2004), "Higher education, sustainability, and the role of systemic learning", in Corcoran, P.B. and Wals, A.E.J. (Eds.), Higher Education and the Challenge of Sustainability: Problematics, Promise and Practice, Kluwer Academic Publishers, Dordrecht, pp. 49-70.

Sterling, S. (2010), "Learning for resilience, or the resilient learner? Towards a necessary reconciliation in a paradigm of sustainable education", Environmental Education Research, Vol. 16 Nos 5/6, pp. 511-528.

Sterling, S. (2017), "Assuming the future: repurposing education in a volatile age", Jickling, B. and Sterling, S. (Eds.), Post Sustainability and Environmental Education: Remaking the Future for Education, Palgrave Macmillan, Cham, pp. 31-45.

Stockholm Resilience Centre (2017), "Stockholm resilience centre's (SRC) contribution to the 2016 Swedish 2030 agenda HLPF report", available at: www.stockholmresilience.org/download/ 18.2561f5bf15a1a341a523695/1488272270868/SRCs2016Swedish2030AgendaHLPFreportFinal.pdf (accessed 9 December 2020). 
Swain, R.B. (2018), “A critical analysis of the sustainable development goals”, in Leal Filho, W. (Ed.), Handbook of Sustainability Science and Research. World Sustainability Series, Springer, Cham, pp. 341-355.

Tainter, J.A. (2006), "Social complexity and sustainability", Ecological Complexity, Vol. 3 No. 2, pp. 91-103.

United Nations Department of Public Information (2020), "Sustainable development goals", available at: https://sustainabledevelopment.un.org/?menu=1300 (accessed 4 May 2020).

Vladimirova, K. and Le Blanc, D. (2015), "How well are the links between education and other sustainable

Sustainable development goals workshop development goals covered in UN flagship reports? A contribution to the study of the Science-Policy interface on education in the UN system", No. 146, UN/DESA Working Paper, New York, NY.

Vladimirova, K. and Le Blanc, D. (2016), "Exploring links between education and sustainable development goals through the lens of UN flagship reports", Sustainable Development, Vol. 24 No. 4, pp. 254-271.

Wals, A.E.J. (2012), Shaping the Education of Tomorrow: 2012 Full-Length Report on the UN Decade of Education for Sustainable Development, United Nations Educational, Scientific and Cultural Organization.

Wang, X.F. and Chen, G. (2003), "Complex networks: small-world, scale-free and beyond", IEEE Circuits and Systems Magazine, Vol. 3 No. 1, pp. 6-20.

Warburton, K. (2003), "Deep learning and education for sustainability", International Journal of Sustainability in Higher Education, Vol. 4 No. 1, pp. 44-56.

Weber, J.M., Lió, P. and Lapkin, A.A. (2019), "Identification of strategic molecules for future circular supply chains using large reaction networks", Reaction Chemistry and Engineering, Vol. 4 No. 11, pp. 1969-1981.

World Commission on Environment and Development (1987), Our Common Future, Oxford University Press, Oxford.

$\mathrm{Xu}, \mathrm{Z}$. and Harriss, R. (2008), "Exploring the structure of the U.S. intercity passenger air transportation network: a weighted complex network approach", GeoJournal, Vol. 73 No. 2, pp. 87-102.

\section{About the authors}

Jana M. Weber obtained her B.Sc. and M.Sc. in environmental engineering from RWTH Aachen University (Germany). She is currently a $\mathrm{PhD}$ student in Chemical Engineering at the University of Cambridge in Prof. Lapkins lab. Her interests cover a broad range of sustainability aspects and complex systems science.

Constantin P. Lindenmeyer studied sustainable energy systems at RWTH Aachen University (Germany); he obtained his MBA from Collège des Ingénieurs in Paris, Munich, and Turin. He is building up the Business Development and Strategy Department at Goldbeck solar.

Piero Liò has $\mathrm{PhD}$ in Complex Systems and non-Linear Dynamics from University of Firenze, Italy, and $\mathrm{PhD}$ in Theoretical Genetics from University of Pavia, Italy. He is currently a Professor in the Department of Computer Science and Technology, University of Cambridge.

Alexei A. Lapkin studied biochemistry at Novosibirsk State University (Russia); he obtained his $\mathrm{PhD}$ in Chemical Engineering from University of Bath. He is a Professor of Sustainable Reaction Engineering at University of Cambridge and an Adjunct Professor at National University of Singapore. Alexei A. Lapkin is the corresponding author and can be contacted at: aal35@cam.ac.uk

For instructions on how to order reprints of this article, please visit our website:

www.emeraldgrouppublishing.com/licensing/reprints.htm

Or contact us for further details: permissions@emeraldinsight.com 